\title{
A Quantity Prediction Model for Reinforced Concrete and Bricks in Education Facilities Using Regression Analysis
}

\author{
Lee, Jong-Kyun ${ }^{1} \quad$ Kim, Boo-Young ${ }^{2} \quad$ Kim Jang-Young $^{3} \quad$ Kim, Tae-Hui ${ }^{4} \quad$ Son, Kiyoung ${ }^{2 *}$ \\ Department of Architectural Plant, Youngsan University, Junam-Dong, Yang-San, 626-300, Korea ${ }^{1}$ \\ School of Architecture, University of Ulsan, Nam-Gu, Ulsan, 680-749, Korea ${ }^{2}$ \\ Department of Education Facility, Anyanggwacheon Office of Education, Dongan-Gu, Anyang, 431-060, Korea ${ }^{3}$ \\ Department of Architectural Engineering, Mokpo National University, Muan-gun, Jeonnam, 534-729, Korea ${ }^{4}$
}

\begin{abstract}
Since the amendment of the law on the private sector investment in social infrastructure in January of 2005, the government has been actively promoting Build-Transfer-Lease (BTL) projects. Notably, most new educational facilities have been built as BTL projects. For these facilities, the unit cost per unit area has been applied to predict construction costs. However, since construction costs are mostly managed after the detailed design phase, the costs can be estimated incorrectly. For this reason, cost management is needed in the planning phase, with a sound approximate estimate to prevent the wasteful use of funds. To address this shortcoming, this study aims to develop a quantity prediction model for education facilities using regression analysis in the planning phase. The developed model is focused on the required quantities of reinforced concrete and bricks. In order to achieve the objective, the data of 44 educational facility projects collected from Gyeonggi-do was used in the regression model. This study can be utilized by major stakeholders to accurately predict construction costs by estimating the appropriate quantities of reinforced concrete and bricks in the planning design phase.
\end{abstract}

Keywords : build-transfer-lease, educational facilities, quantity takeoff, regression analysis

\section{Introduction}

Following the amendments to the law on private sector investment in social infrastructure made in January of 2005, the government has been actively promoting Build-Transfer- Lease (BTL) projects. By the end of 2011, 396 BTL projects had been conducted, with contracts amounting to 23.6 trillion won. Of the projects, education facilities and drainage facilities represent $30.1 \%$ and $26.3 \%$ of the to-

Received : July 2, 2013

Revision received : August 31, 2013

Accepted : September 3, 2013

* Corresponding author : Son, Kiyoung

[Tel: 82-52-259-2788, E-mail: sky9852111@ulsan.ac.kr]

(c)2013 The Korea Institute of Building Construction, All rights reserved. tal number of projects, respectively[1].

Notably, as a part of an initiative to improve the education environment, BTL projects involving educational facilities have been promoted since the law on the construction of educational facilities was established in 2005 by the Ministry of Education \& Human Resources Development. For the facilities, the unit cost per unit area has been applied to predict construction costs[2].

However, since the management of construction costs is focused on after the detailed design phase, management based on approximate estimates in the planning phase are very vulnerable to error. Therefore, it is necessary to develop a model that enables precise prediction of construction cost in the planning phase[3]. 
Thus, the purpose of this study is to develop a quantity prediction model for education facilities in the planning phase using regression analysis. The developed model is focused on predicting the required quantities of reinforced concrete and bricks, since the costs of these items is the main component of total construction costs. The costs of reinforced concrete and bricks occupy 30-35\% and 6-8\% of total costs, respectively[4]. This study can be utilized by major stakeholders to accurately predict construction costs by estimating appropriate quantities of reinforced concrete and bricks in the planning phase.

\section{Research methodology}

In this study, the quantity of reinforced concrete and bricks is analyzed based on the bill of quantity for 44 education facilities, such as elementary, middle, and high schools built for the Gyeonggi Provincial Office of Education from 2006 to 2009. In order to achieve the objective of this study, the previous studies related to BTL and quantity estimation were first analyzed. Second, the bills of quantity for the 44 education facilities built for Gyeonggi Provincial Office of Education from 2006 to 2009 were collected. Third, based on the collected data, the quantity of reinforced concrete and cement block and red brick in each facility are identified. Fourth, the regression model is developed. In the model, the quantity of reinforced concrete and bricks is defined as the dependent variable, and the total floor area, number of classes, and number of floors were defined as the independent variables. Fifth, the correlation analysis is utilized between variables to identify their relationship. In addition, the developed model is verified through the check for normality method.

\section{Literature review}

Many researchers have attempted to conduct studies related to quantity take-off at the planning phase of a construction project, as this can determine the success of the project.

In the area of apartment projects, many studies related to the prediction of construction costs and methods for improving the reliability and accuracy of predictions have been conducted. Park et al.[5] suggested a 3D BIM approximate estimating model using detailed as-built information of previous similar projects. Seong and Kim[6] developed the BIM guideline for apartment projects analyzing the BIM environment in order to promote BIM technology. Lee and Chin[7] have conducted a study regarding the BIM-based quantity take-off of an apartment interior for accuracy and reliability.

In the area of education facilities, while many studies have been conducted related to the design-bid-build delivery method, few studies have been conducted related to the quantity take-off of BTL projects. Kwon et al.[8] suggested a BIM-based estimating method for education facilities to obtain greater accuracy and efficiency by having more information at the planning phase. This study also suggested a reasonable work breakdown structure for bill of quantity. Jeon developed the regression model to predict the quantity of main materials and total construction costs by using the total floor area of design-bid-build projects[4]. In addition, Kim et al.[9] suggested the cost estimating model of structural building elements with an approximate quantity survey method. The model could predict the amount of materials and the cost of construction based on historical similar cases. Based on 145 schools from 2001 to 2005 that were constructed through the design-bid-build delivery method, an artificial 
neural network model for the construction estimate of an education facility at the planning phase was suggested in Kim' s study[2].

In terms of BTL projects, Lee et al.[10] developed a system for estimating the government' $\mathrm{s}$ payment in a BTL project using Visual Basic. The result of the developed system shows a decreased analysis time. In addition, it is possible to analyze the feasibility of a BTL project. Seo explained how to organize the BTL project of an education facility and how to deal with the decision-making for finance cost. Based on the results of the study, Seo emphasized the importance of financial and operation and maintenance cost[11]. In Lee' s study, to identify the difficulties when a BTL project is being planned, a survey of major stakeholders was conducted. The result of the study showed that the priority was to develop the economic analysis system[12]. Kim et al.[13] developed the regression model to predict total construction cost according to the spatial plan of educational facilities by investigating 14 BTL projects from 2008 to 2010.

Therefore, although previous studies have been conducted related to the quantity take-off of apartment and education facility projects built through the design-bid-build delivery method, few studies have been conducted on the BTL projects. This study suggests an accurate and reliable quantity take-off method for BTL projects that uses the regression model.

\section{Data analysis}

\subsection{Descriptive analysis}

This study is conducted based on the bill of quantity for 44 education facilities built from 2006 to 2009 for the Gyeonggi Provincial Office of Education. The quantity of reinforced concrete, cement block, and red brick is collected in each facility. Table 1 provides a descriptive analysis of the collected data.

Table 1. Descriptive analysis

\begin{tabular}{crrrrr}
\hline & N & Min & Max & Mean & $\begin{array}{c}\text { Std. } \\
\text { Deviation }\end{array}$ \\
\hline NumClass & 44 & 18 & 42 & 30.95 & 5.922 \\
Area & 44 & 6,925 & 12,701 & 10,037 & 1,527 \\
Concrete & 44 & 3,958 & 9,876 & 6,122 & 1,428 \\
Reinforce & 44 & 467 & 1,211 & 771 & 154 \\
Cementblock & 44 & 133,221 & $1,327,680$ & 831,723 & 215,533 \\
redbrick & 44 & 130,749 & 517,636 & 335,055 & 87,661 \\
Valid N (listwise) & 44 & & & & \\
\hline
\end{tabular}

In this study, to predict the quantity of reinforced concrete and bricks, the category variable is first set according to whether the project is for an elementary school, a middle school, or a high school. Second, according to the educational facility master plan, the number of classes, the number of floors, and the total floor area are set as the independent variables[2]. Third, as the dependent variables, the reinforcing bar, concrete, cement block and red brick are set. As shown in Table 1, the number of classes ranged from 18 to 42. The total floor area ranged from $6.925 \mathrm{~m}^{2}$ to $12,701 \mathrm{~m}^{2}$.

\subsection{Correlation analysis}

Table 2 represents the correlation results between variables such as the number of classes, the total floor area, the quantity of concrete, reinforcing bar, cement block and red brick. As shown in Table 2, first, since the $\mathrm{p}$-value is less than 0.05 , the number of classes is significantly related to all variables. In other words, as the number of classes is increased, the total floor area and the quantity of concrete, reinforcing bars, cement blocks and red bricks are also increased. Second, the total floor area is positively related to the number of classes, the quantity of concrete, reinforcing bars and cement blocks. However, since p-value is higher than 
Table 2. Correlation Analysis

\begin{tabular}{|c|c|c|c|c|c|c|c|}
\hline & & NumClass & Area & Concrete & Reinforce & Cementblock & redbrick \\
\hline & Correlation & 1 & $.833(\star \star)$ & $.624(* \star)$ & $.632(\star \star)$ & $.423(\star \star)$ & $.332(\star)$ \\
\hline NumClass & Sig. (2-tailed) & & .000 & .000 & .000 & .004 & .028 \\
\hline Area & Correlation & $.833(\star \star)$ & 1 & $.715(\star \star)$ & $.795(\star \star)$ & $.306(*)$ & .200 \\
\hline Area & Sig. (2-tailed) & .000 & & .000 & .000 & .043 & .193 \\
\hline Area & N & 44 & 44 & 44 & 44 & 44 & 44 \\
\hline Concrete & Correlation & $.624(\star \star)$ & $.715(\star \star)$ & 1 & $.816(\star \star)$ & .042 & $.313(*)$ \\
\hline Concrete & $N$ & 44 & 44 & 44 & 44 & 44 & 44 \\
\hline Reinforce & Correlation & $.632(* \star)$ & $.795(\star \star)$ & $.816(\star \star)$ & 1 & .127 & .229 \\
\hline Reinforce & Sig. (2-tailed) & .000 & .000 & .000 & & .411 & .135 \\
\hline Reinforce & $\mathrm{N}$ & 44 & 44 & 44 & 44 & 44 & 44 \\
\hline Cementblock & Correlation & $.423(\star \star)$ & $.306(*)$ & .042 & .127 & 1 & .232 \\
\hline Cementblock & Sig. (2-tailed) & .004 & .043 & .789 & .411 & & .129 \\
\hline \multirow[t]{2}{*}{ Cementblock } & N & 44 & 44 & 44 & 44 & 44 & 44 \\
\hline & Correlation & $.332(*)$ & .200 & $.313(*)$ & .229 & .232 & 1 \\
\hline redbrick & $\mathrm{N}$ & 44 & 44 & 44 & 44 & 44 & 44 \\
\hline
\end{tabular}

0.05 , there is no relationship between the total floor area and the number of red bricks. Third, although there is a significant relationship between the quantity of concrete and the number of classes, the total floor area, and reinforcing bars, there is no relationship with the other variables. Fourth, the number of cement blocks is only related to the number of classes, and the number of red bricks is correlated to the number of classes. As a result, the number of classes and the total area, representing the project size, has a significant relationship with the quantity of all materials.

\subsection{Regression analysis}

\subsubsection{Hypothesis and model development}

In this study, in order to predict the quantity of reinforced concrete and brick, the following hypotheses are established and the regression model is developed. After that, the established hypotheses are verified through the check for normality.

1) The quantity of reinforced concrete used in an education facility can be predicted by the regression model according to the independent variable, the total floor area, the number of floors and the number of classes.

2) The quantity of cement blocks and red bricks can be predicted by the regression model according to the independent variable, the total floor area, the number of floors and the number of classes.

In detail, a regression model with one-way ANOVA analysis is developed in this study. The following Equations (1), (2), (3) and (4) are established to estimate the quantity of reinforced concrete, cement blocks and red bricks, respectively.

$$
\begin{aligned}
& C=\beta_{0}+\beta_{1} \times N C+\beta_{2} \times A+\beta_{3} \times G L+\beta_{4} \times B G L+\beta_{5} \times C L \\
& R=\beta_{0}+\beta_{1} \times N C+\beta_{2} \times A+\beta_{3} \times G L+\beta_{4} \times B G L+\beta_{5} \times C L \\
& C B=\beta_{0}+\beta_{1} \times N C+\beta_{2} \times A+\beta_{3} \times G L+\beta_{4} \times B G L+\beta_{5} \times C L \\
& R B=\beta_{0}+\beta_{1} \times N C+\beta_{2} \times A+\beta_{3} \times G L+\beta_{4} \times B G L+\beta_{5} \times C L
\end{aligned}
$$

Where,

$\mathrm{C}:$ the quantity of concrete $\left(\mathrm{m}^{2}\right)$,

$\mathrm{R}$ : reinforcing bar (ton)

CB : cement block (ea), RB: red brick (ea)

NC : the number of class, A: the total floor area,

GL : the number of floor on the ground

BGL : the number of floor below the ground 
CL : the classification (0:elementary, 1 :middle, 2 : high)

developed model

Table 3. Coefficient Results

\begin{tabular}{|c|c|c|c|c|c|c|}
\hline & Variable & B & $\begin{array}{l}\text { Std. } \\
\text { Error }\end{array}$ & $\begin{array}{c}t \\
\text { value }\end{array}$ & $\begin{array}{c}\mathrm{p} \\
\text { value }\end{array}$ & VIF \\
\hline \multirow{6}{*}{ Concrete } & (Constant) & 241.2 & 1347.5 & .179 & .009 & \\
\hline & Class & 4.0 & 258.0 & .016 & .008 & 1.8 \\
\hline & NumClass & 30.6 & 60.8 & .504 & .017 & 5.0 \\
\hline & Area & 0.6 & 0.2 & 2.472 & .018 & 6.2 \\
\hline & $\mathrm{GL}$ & -363.8 & 325.3 & -1.118 & .271 & 1.4 \\
\hline & BGL & 282.6 & 345.3 & .818 & .118 & 1.0 \\
\hline \multirow{6}{*}{ Reinforcing bar } & (Constant) & 2.7 & 122.2 & -.023 & .022 & \\
\hline & Class & 42.4 & 23.4 & 1.812 & .018 & 1.8 \\
\hline & NumClass & 4.1 & 5.5 & .744 & .032 & 5.0 \\
\hline & Area & .06 & .02 & 2.560 & .015 & 6.2 \\
\hline & $\mathrm{GL}$ & -12.3 & 29.5 & -.418 & .078 & 1.4 \\
\hline & BGL & 24.1 & 31.3 & .772 & .445 & 1.0 \\
\hline \multirow{6}{*}{ Cement Block } & (Constant) & 336,809 & 265,624 & 1.268 & .013 & \\
\hline & Class & 3,624 & 50,861 & -.713 & .031 & 1.8 \\
\hline & NumClass & 13,127 & 11,994 & 1.095 & .041 & 5.0 \\
\hline & Area & 2.1 & 51.7 & .042 & .012 & 6.2 \\
\hline & $\mathrm{GL}$ & 34,725 & 64,127 & .542 & .091 & 1.4 \\
\hline & BGL & $-58,738$ & 68,073 & -.863 & .394 & 1.0 \\
\hline \multirow{6}{*}{ Red Brick } & (Constant) & 252,114 & 103,530 & 2.435 & .020 & \\
\hline & Class & 14,625 & 19,823 & -2.596 & .013 & 1.8 \\
\hline & NumClass & 1,321 & 4,674 & .283 & .029 & 5.0 \\
\hline & Area & 21.6 & 20.1 & 1.073 & .001 & 6.2 \\
\hline & $\mathrm{GL}$ & $-17,1$ & 24,9 & -.685 & .497 & 1.4 \\
\hline & BGL & 22,784 & 26,532 & .859 & .396 & 1.0 \\
\hline
\end{tabular}

Table 3 represents the coefficient of the regression models. The Class variable shows the categoriy variable. In the variable, 0,1 and 2 represent the elementary, middle and high schools, respectively.

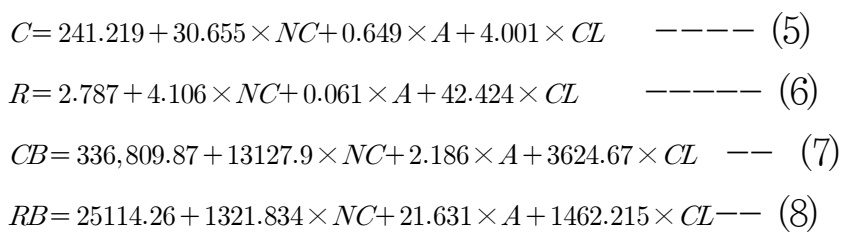

Table 4 shows the $\mathrm{R}^{2}$ of each regression model. As the coefficient of determination, the $\mathrm{R}^{2}$ indicates how well data points fit a line or curve. In other words, the $\mathrm{R}^{2}$ provides a measure of how well observed outcomes are replicated by the model.
Table 4. R Square Results

\begin{tabular}{cccrr}
\hline Model & $\mathrm{R}$ & $\mathrm{R} 2$ & $\begin{array}{c}\text { Adjusted R } \\
\text { Square }\end{array}$ & $\begin{array}{r}\text { Std. Error of } \\
\text { the Estimate }\end{array}$ \\
\hline $\begin{array}{c}\text { Concrete } \\
\text { Reinforcing } \\
\text { bar }\end{array}$ & 0.737 & 0.542 & 0.481 & 1041.191 \\
Cement block & 0.634 & 0.675 & 0.631 & 94.455 \\
Red brick & 0.530 & 0.481 & 0.462 & 993.491 \\
\hline
\end{tabular}

** Predictors:(Constant), NC, A, GL, BGL, CL.

* Dependent Variable: C, R, CB, RB.

With the adjusted $\mathrm{R}^{2}$ developed in this study, the quantities of concrete, reinforcing bars, cement blocks, and red bricks are shown as 0.481, 0.631, 0.423 and 0.462 , respectively. Therefore, using the regression model, the quantities of concrete and reinforcing bar can be predictable as $48.1 \%$ and $63.1 \%$, respectively. In addition, cement block and red brick can be estimated as $42.3 \%$ and $46.2 \%$. Furthermore, the rest of each regression model can be explained by the unknown variables.

\subsubsection{Check for validity}

Before proceeding to the interpretation, it is essential to confirm that the residuals are normally distributed. As the method to check for normality, Table 5 shows whether or not the residuals are normally distributed numerically.

Table 5. Check for Normality

\begin{tabular}{cccccccc}
\hline & \multicolumn{3}{c}{ Kolmogorov-Smirnov } & \multicolumn{3}{c}{ Shapiro-Wilk } \\
& Statistic & df & Sig. & Statistic & df & \multicolumn{1}{c}{ Sig. } \\
\hline Reinforce & .072 & 44 & .200 & .984 & 44 & .805 \\
Cementblock & .121 & 44 & .103 & .935 & 44 & .056 \\
redbrick & .089 & 44 & .200 & .986 & 44 & .852 \\
\hline
\end{tabular}

Generally, when the sample size is higher than 50, the Kolmogoro-Smirnov test is used. In this study, both tests are used to check for normality. As shown in Table 5, p-value is higher than 0.05, which proves that the residuals are normally distributed. 
In addition, as shown in Figure 1, a Q-Q plot of standardized residuals confirms that the models are normally distributed. Therefore, the check for normality proves that the developed models are significant and can be used to predict the quantity of materials.

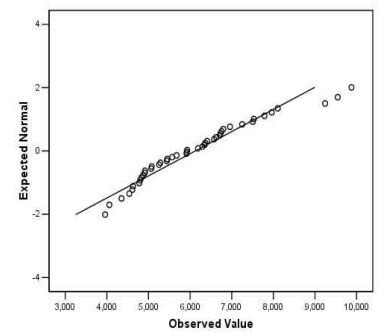

(1) Concrete

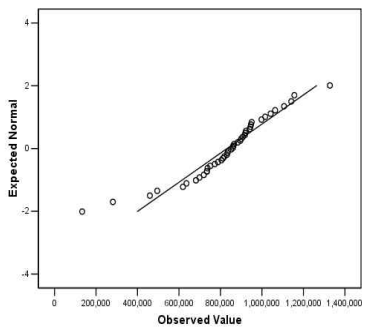

(3) Cement Block

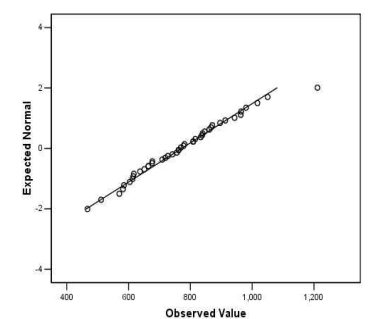

(2) Reinforcement

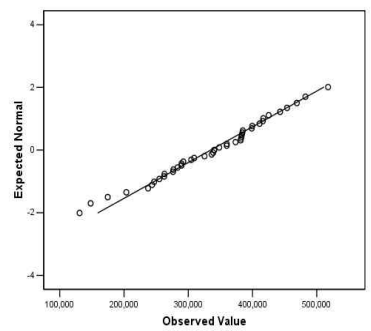

(4) Red Brick
Figure 1. Q-Q plot of standardized residuals for each model

\section{Conclusion}

This study suggests a quantity prediction model for reinforced concrete and bricks in education facilities in the planning phase using regression analysis. The data of the 44 education facilities projects collected from Gyeonggi-do was used in the regression model. The quantity of reinforced concrete and bricks was used as the dependent variable, and as the independent variable, the total floor area, number of classes, and number of floors were collected.

The result of the correlation showed that there is a significant relationship between the number of classes, the total floor area, and the quantity of materials, regardless of the number of floors. In particular, since the $\mathrm{R}^{2}$ of each developed model is
$0.481,0.631,0.423$ and 0.462 , the quantity of concrete, reinforcing bars, cement blocks, and red bricks can be explained $48.1 \%, 63.1 \%$, 42.3\%, and $46.2 \%$, respectively, based on the developed model. In other words, it indicates that there are unknown variables to predict the quantities. Therefore, in the future, a study should be conducted that considers unknown variables such as the size of each class or other influencing factors. In addition, the validity of the model to quantify the materials was confirmed since there is no heteroscedasticity problem found through the check for normality.

This study can be utilized for major stakeholders to correctly predict construction costs by estimating the appropriate quantities of reinforced concrete and bricks in the planning design phase. However, since the data were collected from 2006 to 2009 and only involve facilities built for the Gyeonggi Provincial Office of Education, the scope of this study is limited. Therefore, in the future, additional research should be performed after collecting data on education

\section{Acknowledgements}

This work was supported by the 2013 Research Fund of Youngsan University.

\section{References}

1. Ministry of Strategy and Finance. Social overhead capital status and improvement [Internet]. Sejong: Ministry of Strategy and Finance; 2013 May 31[cited 2013 June 16]. 166 p. Available from: http://www.mosf.go.kr/policy/policy01.jsp.htm

2. Kim CY, Son JH. A study on the model of artificial neural network for construction cost estimation of educational facilities at conceptual stage. Journal of the Architectural Institute of Korea. 2006 Jun;7(4):91-9.

3. Kim SM, Cho JH, Lee JS, Chun JY. Cost estimating model of structural elements using approximate quantity survey in 
preliminary building design phase. Journal of the Architectural Institute of Korea. 2009 Dec;25(12):155-64.

4. Jeon YI. A study on the analysis and the prediction of the cost for the school construction [master's thesis]. [Daejeon (Korea)]: Mokwon University; 2004. 133 p.

5. Park YJ, Won SK, Han CH, Lee JB. A study on 3D BIM collaborative approximate estimating model of structural work for apartment projects. Journal of the Architectural Institute of Korea. 2011 Jun;27(6):123-30.

6. Seong JH, Kim GH. A study on the development of BIM guideline for apartment house. BIM conference. 2012 May;2(1):5-6.

7. Lee MK, Chin SY. A study on the accuracy of BIM-based quantity take-off of apartment interior. Journal of the Korea Institute of Construction Engineering and Management. 2013 Jan;14(1):12-22.

8. Kwon OB, Son JH, Lee SH. Study on the application of 3D-base BIM for school facilities to increase cost management efficiency. Journal of the Korea Institute of Building Construction. 2010 Dec;10(6):49-60.

9. Kim $\mathrm{JH}$, Lee $\mathrm{MH}$, Lee HK. The estimation of construction cost by using the actual information in the educational building projects. Journal of the Regional Association of Architectural Institute of Korea. 2005 Nov;7(4):89-96.

10. Lee CK, Cho BH, Park TK. A survey on the persons in charge for economic estimation analysis and improvement of BTL projects. Journal of Korea Institute of Construction Engineering and Management. 2007 Aug;8(2):73-80.

11. Seo CS. Financing of educational Infrastructure in private investment(Build-Transfer-Lease). Journal of the Architectural Institute of Korea. 2006 Feb;50(2):89-91.

12. Lee CK, Cho BH, Jung YH, Park TK. A study on developing the calculation system of disbursement for government on the BTL projects. Journal of Korea institute of Construction Engineering and Management. 2009 Mar;10(2):93-101.

13. Kim JW, Lee BR, Kim JH, Kim JJ. A study on construction cost estimation model according to the spatial planning of educational facilities using regression analysis. Journal of Architectural Institute of Korea. 2011 Aug;27(10):103-10. 